\title{
FUTURE DEEP SPACE PROPULSION SYSTEMS
}

\author{
ERNST STUHLINGER
}

3106 Rowe Drive, Huntsville, AL, 35801, U.S.A.

\begin{abstract}
Among several potential future deep space propulsion systems, the two which are closest to realization are selected for closer consideration: solar-electric, and nuclearelectric propulsion. In particular, the paper describes a manned Mars mission using a particle bed reactor and Brayton cycle converter as power source. Technical details of the design and the mission profile of a 4-astronaut expedition to Mars, and a proposed course of action for project implementation are presented.
\end{abstract}

\section{Introduction}

Much has been talked and written about future propulsion systems, other than our conventional, time-honored chemical rockets - propulsion systems that can take scientific observatories, unmanned and manned, into orbit, to the Moon, to planets, toward the Sun, and to other places in the solar system.

A number of such propulsion systems have been under consideration for years. They may be grouped into three classes (Table 1): First, 'passive' systems, such as gravity assist or 'planetary flyby' schemes; and the solar sail. Second, 'near-future' systems, among them electric propulsion which includes ion, arc jet, and MPD systems, and also nuclear thermal rockets, of which the famous Nerva project, and the gas core reactor, are examples. The third group contains such far-out concepts as fusion reactor systems, anti-matter propulsion systems, and photon rockets.

\section{Selection of Preferred Future Propulsion Systems}

Future propulsion systems should have, besides the basic virtues of great reliability, two features in which they surpass existing rocket systems: They should offer a greater propulsive capability, and they should permit higher payloads for the same initial systems mass (Table 2). These features would provide shorter mission times; they would allow more scientific and exploratory activities; and they would lead to a greater overall success of the mission.

Rather than elaborating on all these systems and adding some further speculations, this paper will concentrate on two of the advanced systems which are far closer to realization than the other propulsion schemes, and which will certainly put their imprints on the next phase of the space program. These two systems are the solar-electric and the nuclear-electric propulsion concepts. The two of them have already a long joint history of analytical studies, laboratory development, and even flight testing. They also have features that are very advantageous for many of our space projects of the next 20 to 30 years, particularly the further exploration of the Moon, the Sun, the planets and their moons, comets, and asteroids. They even offer very attractive possibilities for manned missions to the surface of the planet 
Mars, a project that received new impetus recently through the Human Exploration Initiative established by President Bush.

\section{Electric Space Propulsion}

Electric propulsion systems are by no means novel concepts (Table 3). Tsiolkovskii talked about electric rockets almost one hundred years ago; Goddard made some theoretical and experimental studies in 1906; and Oberth wrote about electric propulsion systems in the early 1920s.

Systematic analytical work on electric propulsion began in 1947, and around 1955 the first laboratory experiments with electric thrusters started at the ElectroOptics Company in Pasadena. A few years later, Harold Kaufman at the NASA Lewis Laboratory demonstrated his Kaufman thrusters, followed in 1960 by Horst Loeb in West Germany who used a slightly different ionization scheme. A few years later, flight testing of thrusters onboard satellites began, confirming the validity of the expectations put into electric thrusters. During the following 15 years, about three dozen flight tests were successfully performed in the United States, and also in some other countries.

In spite of all this very promising development work, no real space mission with electric thrusters has materialized as yet, simply because there were always other projects with higher priorities.

Table 4 shows the principles of chemical and electric rocket engines. They are largely identical, except that electric rockets need an external source of power. That source could be the Sun, or a nuclear reactor. Solar power has the advantage of being environmentally clean. However, the density of solar flux decreases with the square of increasing solar distance; also, there is no solar power on the shadow side of the Earth. Solar-electric propulsion is quite attractive for unmanned space missions as far out as the Ateroid Belt, and even for freight transporation to the Moon. Nuclear-power propulsion systems, because of the danger of contamination in case of a catastrophic system failure (such as the impact of a piece of orbital debris), should be operated only at distances greater than about $40,000 \mathrm{~km}$ from Earth.

Details of electric (ion) thrusters are shown in Table 5. Table 6 gives some comparative design and performance data of chemical and of electric rocket systems. While the thrust forces and hence the accelerations of electric systems will always be small, obtainable velocity increments are considerable, and so are the payload ratios of electric rockets. An example of an unmanned solar-electric spacecraft for a comet rendezvous and sample return mission with a $50 \mathrm{kWe}$ photo-voltaic power source is shown in Table 7.

Several different systems to convert reactor heat into electricity are available. Table 8 illustrates a particle bed reactor with Brayton-cylce converters; there are two parallel turbo-generator sets, counter-rotating to avoid torques on the spacecraft. A powerplant of this type could generate $10 \mathrm{MWe}$, with a total reactor thermal power of $50 \mathrm{MWth}$ [Ref. 1]. 


\section{Nuclear-Electric Mars Mission}

As soon as a reliable, efficient propulsion system of the solar-electric or the nuclearelectric type is available, a broad array of deep space missions will become feasible. One specific mission with a 10MWe nuclear power supply, a manned roundtrip to the planet Mars, will be described in more detail.

The primary objectives of a manned Mars mission will be (1) to assure the safe return of the astronauts, (2) to provide a rich harvest of scientific exploration and technical knowledge, and (3) to become the first step of a continuing program of human exploration of Mars, leading eventually to a permanently occupied base on the planet (Table 9).

These basic objectives immediately lead to a planning philosophy, shown on Table 10. The astronauts should not be left in space longer than about one year. The severe restrictions of "life in the can", much of it even within a space suit, should not be imposed upon them beyond that limit. Besides known physiological effects, there are psychological factors that must not be underestimated. Comfort and potential privacy for the astronauts should be assured. On that first mission, the staytime on Mars should not be longer than 4 to 6 weeks. While traveling through near-Earth space, the transit through the Van Allen Belts should be as short as possible.

\section{Artificial Gravity?}

Should there be artificial gravity during the long transfer periods between Earth and Mars? To paraphrase Prince Hamlet: "To ' $g$ ' or not to ' $\mathrm{g}$ ', that is the question..." It seems that among those astronauts who have spent weeks or months in orbit, and also among the serious space mission planners, there is definite preference for artificial gravity, perhaps $0.38 \mathrm{~g}$ (like on the Martian surface), perhaps even a value that changes gradually from 1.0 to $0.38 \mathrm{~g}$ during the transfer. Designing a rotating arm systern as part of the transfer spacecraft does not appear to be problematic. A system of this kind could be operated and tested on the Space Station Freedom several years before it would become a part of the Mars vehicle, and much-needed research on artificial gravity could be performed long before the design of the Mars vehicle has to be finalized (Table 11).

\section{Supporting Facilities}

Irrespective of the details of a manned Mars transfer vehicle, and even of its mode of propulsion, a heavy lift vehicle will be needed to transport the components of the Mars mission into low Earth orbit (LEO) for assembly. A heavy lift vehicle of this type will be needed for other space projects even before the start of the Mars mission, among them the Space Station Freedom, traffic into geosynchronous orbit (GEO), freight and manned flights to the Moon, and as launcher for unmanned large planetary and interplanetary spacecraft. It may be assumed that by the time a manned Mars mission takes shape, there will be a heavy lift launch vehicle (HLV), an orbital maneuvering vehicle (OMV) for transports in the vicinity of the space station, an orbital transfer vehicle (OTV) that can operate between LEO and GEO, 
a life support system that recycles water, and a booster rocket engine, burning $\mathrm{H} 2$ and $\mathrm{O} 2$ and developing about 100,000 N (10 tons) of thrust, for use between LEO and GEO (Table 12).

\section{Profile of the Proposed Manned Mars Mission}

A manned mission to Mars may be structured as follows (Table 13): After assembly in orbit, the complete and manned vehicle will be boosted chemically to nearly escape velocity. During this boost phase, there will be trusses to support the long arms with the habitat capsules (not rotating at that time), as shown in Table 14 . The nuclear reactor will be started up at a distance of about $40,000 \mathrm{~km}$ from Earth. The propellant, mercury, which doubles as a protective layer around the radiation shelter, will not contaminate LEO, nor will a 'hot' reactor endanger the Earth, or be exposed to orbital debris. The vehicle will proceed to Mars, and will spiral down into a relatively low orbit $(500 \mathrm{~km}$ ?) where it will detach the landing craft (Mars Excursion Vehicle, MEV). Return to Earth will be by nuclear-electric thrust only. After transfer, the vehicle will spiral down into a high (approx. GEO) orbit, from where the astronauts will return to Earth by OTV and Shuttle. No aerobraking will be necessary. The Mars transfer vehicle will not come closer to Earth than GEO. If so desired, the vehicle, including its reactor, could be refurbished in Geo and used again for another mission, or it could propel itself out into space.

There will be two identical transfer vehicles, each of them manned by two astronauts (Table 15), and one similar, but unmanned vehicle for freight (Table 16). Each of the manned vehicles will carry a landing craft (MEV), and the unmanned vehicle will carry two landing crafts. Each landing craft will carry an ascent vehicle, providing substantial redundancy. In an emergency, one ascent vehicle could carry all four astronauts; also, one manned transfer vehicle could accomodate four astronauts (Table 17). Design data for the transfer vehicles are shown in Table 18.

The unmanned freight vehicle will travel first and deploy its MEVs with ascent vehicles, habitat, life support, shelter, and roving vehicle on the surface of Mars. Only when this 'home away from home', including Hertz car and two ascent vehicles, is firmly established on Mars and in operating condition, will the two manned transfer vehicles leave LEO for their voyage to Mars (Table 19).

Details of the transfer trajectories between Earth and Mars, and back to Earth, are shown in Figs. 20 and 21.

It should be noted that the same vehicle designs, and the same mission profile, can be used for further missions to Mars after the first exploratory mission. In particular, both the manned and unmanned versions will represent proper transfer vehicles at the time when a Martial base is to be established, and when regular traffic between Earth and the Mars base is to be maintained (Table 22).

\section{A Proposal for Action}

Implementation of a manned mission to Mars could proceed along the following course of action (Tables 22 and 23): First, a decision should be made to choose the nuclear-electric propulsion system for the mission. Then, development of the major 
components - thrusters, nuclear power source, artificial gravity system, life support system, Mars rover - should be started. It should be noted that all these components will be used and even needed on other space projects planned for the near future, even if no manned Mars mission should materialize; for example, electric thrusters will be needed on unmanned solar-electric vehicles for lunar freight and deep space missions; nuclear-electric power sources will be needed for lunar activities, and for unmanned deep space exploration; life support systems sill be needed on the Space Station, and on the Moon; artificial gravity research will be performed on the Space Station; roving vehicles operating under low gravity will be needed on the Moon.

While these developments are underway, a vigorous program of Mars observations should be pursued from the ground, from orbit, from the Moon (once it is revisited), and from unmanned Mars probes. Sample return missions to Mars should be included. This program will certainly be parallelled by similar programs in Europe, the USSR, Japan, perhaps China. There should be a continuous exchange between nations not only of thought, data, observational results, and increasing knowledge, but also of plans for future projects.

Systematic planning for a manned mission to Mars, supposedly taking place around the year 2015, need not be started before about 2000. By that time, all the major components will be far advanced in their development, and even in their testing and applications. Knowledge about environmental details of Mars will have increased decisively. When that systematic planning phase for the Mars mission begins, the time will have come to consider possibilities of sharing project responsibilities with other nations.

\section{Acknowledgements}

Present work has been partially supported by General Dynamics Space Systems, San Diego.

\section{References}

Powell, J.R., et al.,: "Particle Bed Reactor Multimegawatt Concepts", Brookhaven National Laboratory; Babcock and Wilcox; Grumann Aerospace Corporation; and Garrett Corporation; BNL-39495; March 1987.
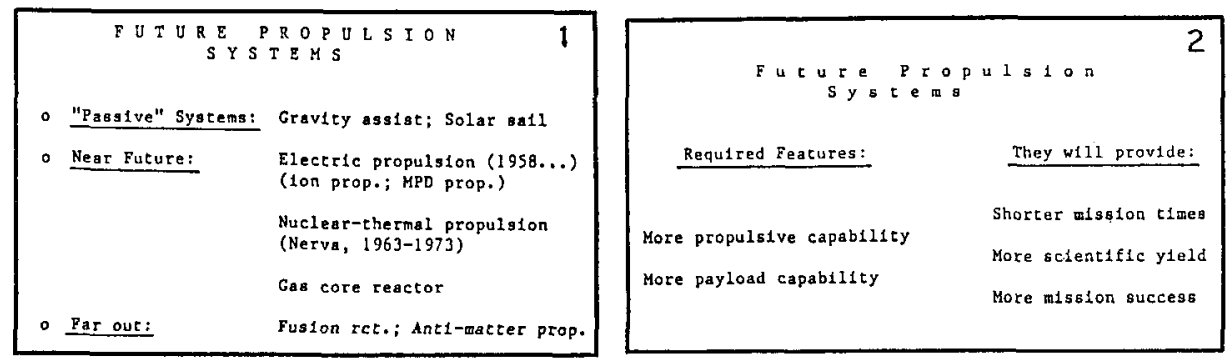

Tables $1-2$ 


\begin{tabular}{|c|c|}
\hline & 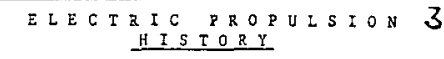 \\
\hline 1895 & Z1olkovak11; 1906: Goddard; 1920a: Oberth \\
\hline $\begin{array}{l}1947 \\
1955\end{array}$ & $\begin{array}{l}\text { Comprehensfve analytical otudles began } \\
\text { Laboratozy work began }\end{array}$ \\
\hline 1957 & Kauf aan thrusterb; 1960 Loeb chruscers \\
\hline 1964 & Flight cesting scarted \\
\hline & About 35 flighrs of Etec. Ehrusters \\
\hline $1968 \cdots$ & E1. Prop. ready and watling for atsstons \\
\hline
\end{tabular}
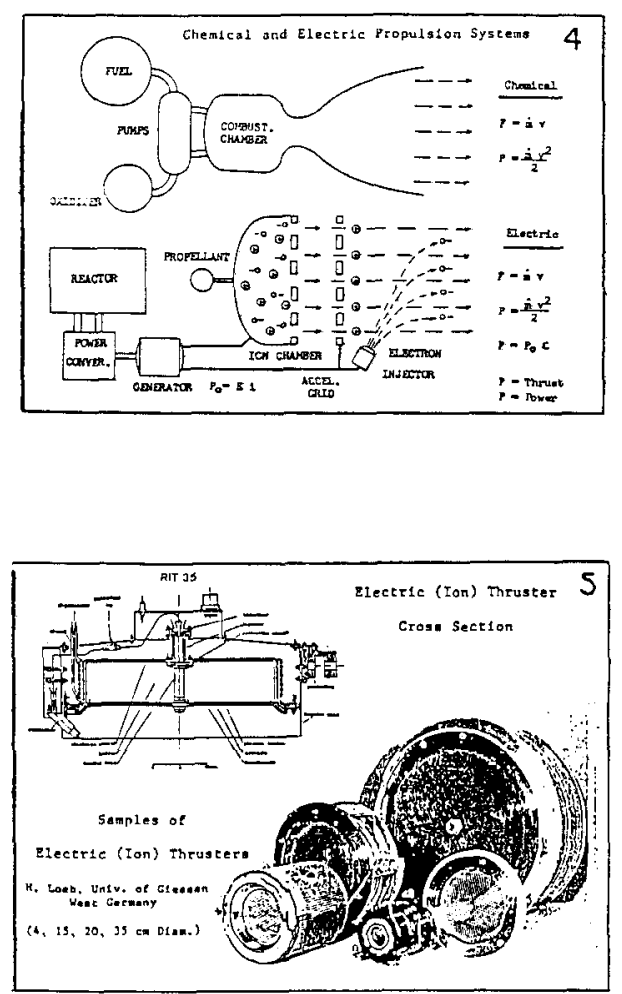
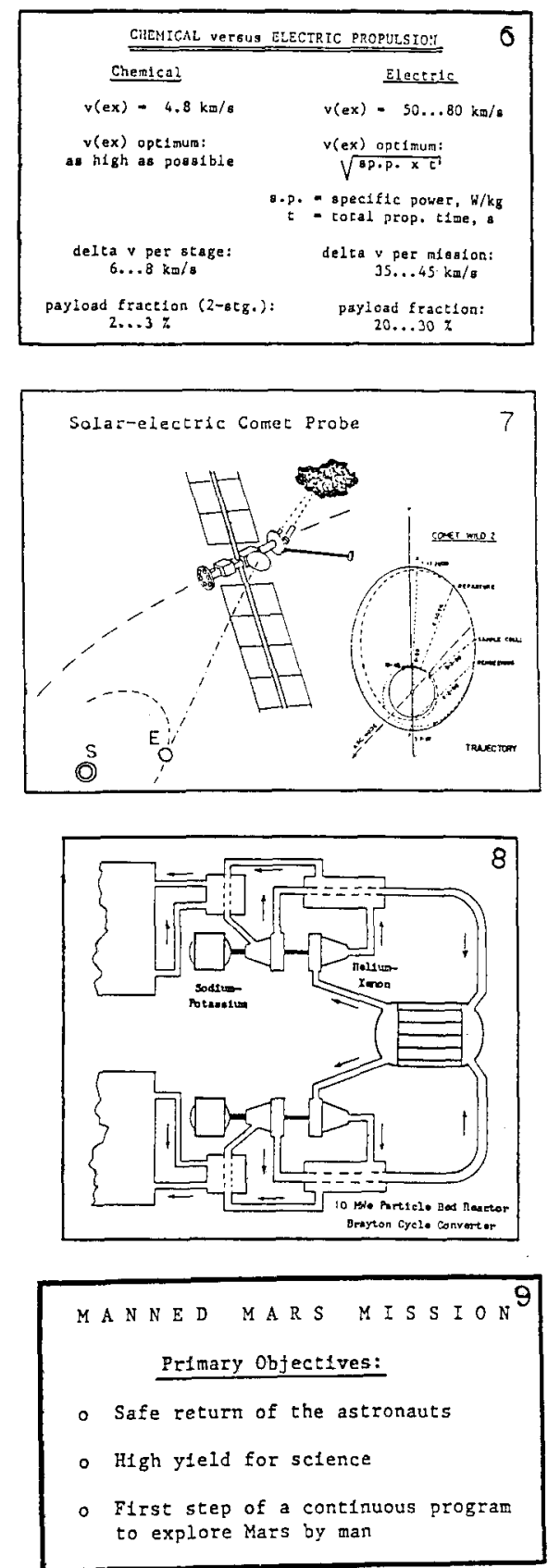

Tables 3-9 
$M$ I S I I N P L A N INO PH I L OSOP H Y

- Total alssion t1me epprox. 1 year

Fast pasage chrough Van Allen Belta

- Attificial gravity for astronauts $(0.4 \mathrm{~g})$

- Comfort and potential privacy for astronauts

Staytige on Mars surface 4 to 6 weeks

- F1rsc step in a continuting Mars expl. progran

MANNED MARS MISSION

To " $g$ " or not to " $g$ ", that is the question...

- Astronauts must be ln top phyalcal condition when they arrive on the Martian surtace

- "g" Is desirable for health, and for confort

- Mosc astronauts are opting for " $g$ "

Actiticial gravity on che Mars transfer vehicle will not be costly in mass or complexity

- " $g$ " capsules to be tried out on Space Station

MANNED MARS HISSION 12

It is assumed that by 2015 , there ul11 be:

- A heavy-l1ft vehicle (180 e from Estrh to LEO)

- An orbical maneuvering short-range vehicle

An orbtcal leo-co-GEO tranefer vehiele

- A water-recycling life oupport syscem

- A $100,000 \mathrm{~N}$ (10 ton) $12-02$ rocket engine

MARS MISSION PROFIL

- Manned and freight vehicles will be similar.

- Fre1ghterg (1 or 27) will atay 1a epace, manned veh. ( 2 or 37 ) w111 tecurn to GEO.

- Vehicle assembly in LEO; boost to escape from LeO (w1th astronauts) by $\mathrm{H} 2-02$ booster.

- Manned yeh. w111 carry 1, freighter(s) 2 Mara Excurston Yeh.: each with an ascent vehdcle.

- At leagt one fralghter MEV will carry a com fortable habtiat, sheler, and a rover.

- Astronauts w111 leave Earth only when MEVe from freighter(s) are firaly eacablished an Mars.
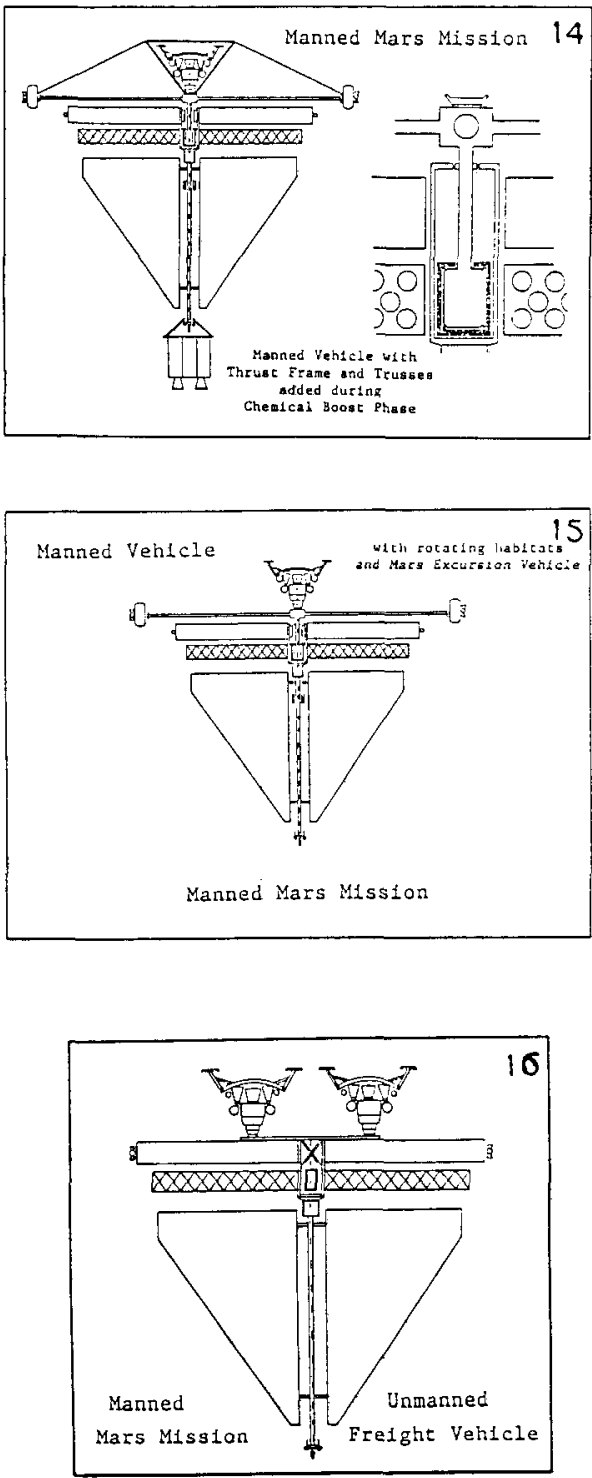

Tables $10-16$ 
MANNED MARS MISSION 17

$$
\begin{aligned}
& \text { opt } 1 \text { mu } \mathrm{m} N \text { u d b e } \\
& \text { of } \\
& \text { As c r O n a u t } s
\end{aligned}
$$

If misston is limlted to 2 astronauts per veh., and 2 manned vehicles per mission, then $1 \mathrm{n}$ an energency a11 4 astronauts can ascend from Mars in one ascent veh., and return to Earth in one manned vehicle.
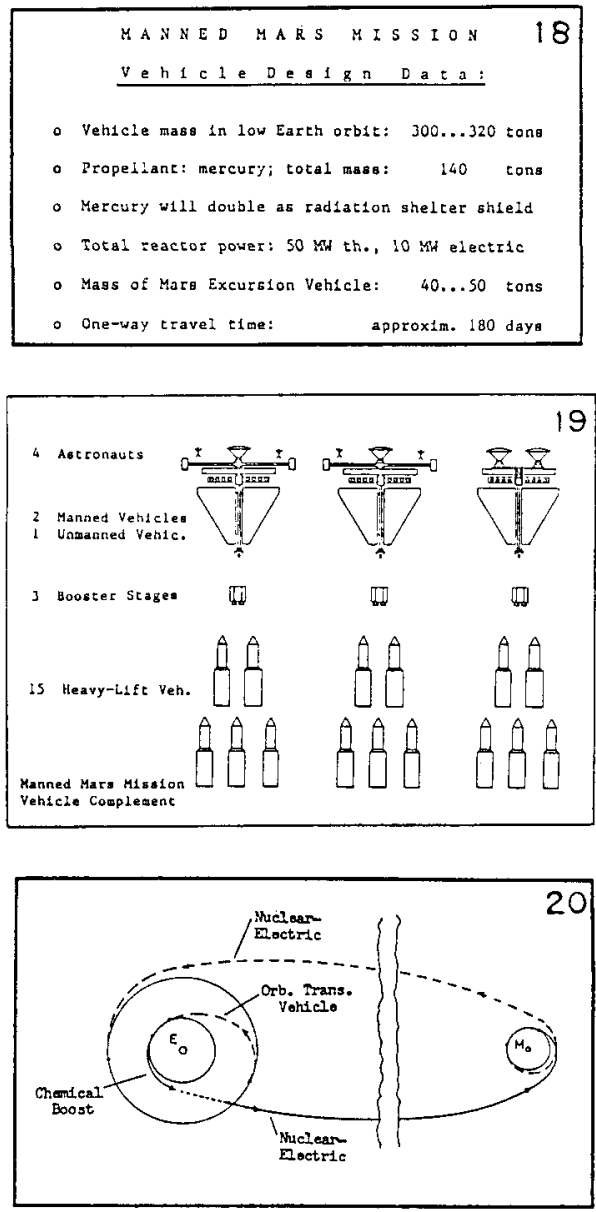

Earth - Mars Trajectory

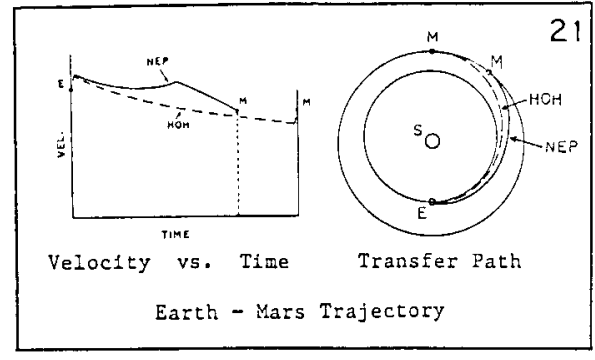

N U CLEAR-ELECTRIC MISSIONS

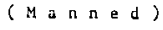

Mars: Exploration misstons

Estabifingent of Base

Regulas cratalc Earth-to-Base

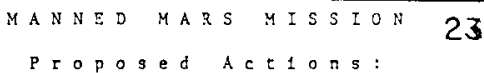

- Decision to use nuclear-electric propulsion

- Immediate development of major components

o Use of ali components on unmanned missions

- Continuing unmanned explotation of Mars

- Systematic planning and preperation of manned Mars misaton, beginning around 2000

- Target date for start of m1ssion: 2015...2017

Tables $17-24$ 